\title{
Gold Nanoparticle Self-Aggregation on Surface with 1,6-Hexanedithiol Functionalization
}

\author{
Maksym Stetsenko ${ }^{1,2}{ }^{(}$, Tetiana Margitych ${ }^{3}$, Serhii Kryvyi $\left.{ }^{2,4}{ }^{(}\right)$, Lidia Maksimenko ${ }^{2}$, \\ Ali Hassan ${ }^{1}{ }^{1}$, Svitlana Filonenko ${ }^{5}$, Baikui $\mathrm{Li}^{1, *}$, Junle $\mathrm{Qu}{ }^{1, *} \mathbb{1}$, Elke Scheer ${ }^{6}$ and \\ Sergii Snegir $6, *(\mathbb{B}$
}

1 Key Laboratory of Optoelectronic Devices and Systems of Ministry of Education and Guangdong Province, College of Physics and Optoelectronic Engineering, Shenzhen University, Shenzhen 518060, China; stetsenkomax@gmail.com (M.S.); 15alirao@gmail.com (A.H.)

2 V. Lashkaryov Institute of Semiconductor Physics, National Academy of Sciences of Ukraine, 03680 Kyiv, Ukraine; serkriviy@gmail.com (S.K.); maximenko_lida@ukr.net (L.M.)

3 Kyiv Institute for Nuclear Research, National Academy of Sciences of Ukraine, 03680 Kyiv, Ukraine; margtanya@gmail.com

4 Institute of Physics, Polish Academy of Sciences, 02-668 Warsaw, Poland

5 Pisarzhevski Institute of Physical Chemistry, National Academy of Sciences of Ukraine, 31 Prospect Nauky, 03028 Kiev, Ukraine; svitmail@ukr.net

6 University of Konstanz, Department of Physics, Universitätsstraße 10, 78464 Konstanz, Germany; Elke.Scheer@uni-konstanz.de

* Correspondence: libk@szu.edu.cn (B.L.); jlqu@szu.edu.cn (J.Q.); sergii.snegir@uni-konstanz.de (S.S.)

Received: 4 February 2020; Accepted: 6 March 2020; Published: 11 March 2020

\begin{abstract}
Here we study the morphology and the optical properties of assemblies made of small $(17 \mathrm{~nm})$ gold nanoparticles (AuNPs) directly on silicon wafers coated with (3-aminopropyl)trimethoxysilane (APTES). We employed aliphatic 1,6-hexanedithiol (HDT) molecules to cross-link AuNPs during a two-stage precipitation procedure. The first immersion of the wafer in AuNP colloidal solution led mainly to the attachment of single particles with few inclusions of dimers and small aggregates. After the functionalization of precipitated NPs with HDT and after the second immersion in the colloidal solution of AuNP, we detected a sharp rise in the number of aggregates compared to single AuNPs and their dimers. The lateral size of the aggregates was about $100 \mathrm{~nm}$, while some of them were larger than $1 \mu \mathrm{m}$. We propose that the uncompensated dipole moment of the small aggregates appeared after the first precipitation and acts further as the driving force accelerating their further growth on the surface during the second precipitation. By having such inhomogeneous surface coating, the X-ray reciprocal space maps and modulation polarimetry showed well-distinguished signals from the single AuNPs and their dimers. From these observations, we concluded that the contribution from aggregated AuNPs does not hamper the detection and investigation of plasmonic effects for AuNP dimers. Meantime, using unpolarized and polarized light spectroscopy, the difference in the optical signals between the dimers, being formed because of self-aggregation and the one being cross-linked by means of HDT, was not detected.
\end{abstract}

Keywords: aggregation; dimers; AuNPs; self-assembly; surface; 1,6-hexanedithiol; APTES; optics; morphology

\section{Introduction}

Gold nanoparticles (AuNPs) attract much attention owing to their unique optical, electronic, and catalytic properties. They have allowed development of different prototypes of devices for sensing [1,2], detecting [3], and imaging [4,5]. Further progress in designing AuNP-based devices depends on the 
ability to fabricate complex assemblies with tailored optoelectronic properties. Different approaches have already been proposed to follow this idea.

A multi-stage ligand exchange procedure [6-8] in a solution allows for the formation of monometallic dimers [9,10], trimers [11], long AuNP chains [12,13], or hybrid systems made of polystyrene-coated gold [14] or silver-gold [15] nanoparticles. However, during the synthesis, in addition to the dimers, larger structures with a different size and shape appear. Therefore, the process of the dimer separation becomes a complicated task. A DNA origami was used recently $[8,16]$ to design more controlled self-assembled nanostructures with high yield. This approach allows for programmable spatial positioning of functionalized nanoparticles in a confined volume. As a result, 2D and 3D periodic assemblies of isotropic/anisotropic AuNPs with different spatial separation can be created. Self-assembly of AuNPs on a micro-scale requires exploiting their high affinity toward specific surface functional groups. Gold substrates coated with dithiols, for instance, can efficiently anchor AuNPs $[17,18]$. The surface of glass, silicon, and indium tin oxide (ITO) pre-coated with (3-aminopropyl)trimethoxysilane (APTES) can efficiently attach AuNPs [19-21] as well as NPs made of $\mathrm{Ag}$ [22,23], $\mathrm{SiO}_{2}$ [24], $\mathrm{TiO}_{2}[25,26], \mathrm{Fe}_{2} \mathrm{O}_{3}$ [27,28], or Y-zeolites [29].

When an APTES-coated surface is used, a static interaction of the positively charged aminopropyl terminal groups and negatively charged cores of AuNPs, being stabilized by means of trisodium citrate in water, is employed. By changing the time of the substrate immersion in the colloid, the resulting surface density of single AuNPs can be adjusted. The contact point of the AuNPs with the substrate is quite small. Therefore, the remaining free AuNP surface can be further functionalized with different molecules either for studying the interaction of the localized surface plasmon resonance (LSPR) with their surrounding media [30] or for the synthesis of mono- and bi-metallic [31,32] NP dimers.

Thus, using APTES is the most straightforward approach for the immobilization of AuNPs on a large area. However, obtaining a coating with only single AuNPs well separated from each other is rather difficult to achieve because of the intrinsic presence of self-aggregated AuNPs. Their appearance is associated with the quality of the APTES coating [19]. The smoother the aminosilane monolayer is at the molecular scale, the lower will be the amount of aggregated AuNPs. Several approaches have been proposed to improve the quality of the APTES coating. At first, the substrate roughness has to be minimized $[33,34]$. Then, the surface density of the $\mathrm{OH}$ - terminal groups has to be sufficiently enhanced to be able to bind all three ethoxy groups of the APTES molecules. Then the optimal concentration of the APTES has to be used, and a suitable time of a substrate immersion has to be chosen [33]. Even with all of these steps, some ethoxy groups of the APTES can remain not completely linked to the surface. This can be improved partially by elevating the APTES solution temperature to $\sim 70{ }^{\circ} \mathrm{C}$ during substrate silanization [35] or by post-annealing of the APTES-coated substrate at $\mathrm{T}=600^{\circ} \mathrm{C}$ in vacuum [19]. However, even with these treatments, finding the majority of the $-\mathrm{NH}_{2}$ groups of the APTES monolayer pointing away from the surface is difficult to achieve [36] and, thus, completely suppressing self-aggregation of AuNPs is impossible.

In our previous article [20], we developed and tested the method of solid-state formation of dimers created from small AuNPs ( 18 nm) cross-linked with 1,9-nonadithiol (NDT) molecules on glass surfaces. In addition to the dimers, we detected the formation of the aggregates that led to the appearance of collective oscillation modes, which were self-similar to AuNP dimers. We concluded that the study of the optical properties of AuNP dimers on the surface requires further development.

Therefore, this work aims at creating cross-linked self-assemblies of AuNPs with a naturally formed amount of aggregates on silicon (Si) wafers to understand the possibility of detecting the optical signal from single AuNPs and their dimers. We used smooth silicon (Si) wafers instead of the glass [20] to minimize the number of defects in the APTES monolayer that might appear due to intrinsic wafer defects [33,34]. With atomic force microscopy (AFM), scanning electron microscopy (SEM), X-ray diffraction (XRD), and X-ray reflectivity (XRR), we studied at first the morphology of the cross-linked AuNP assembly, which was generated directly on the APTES-coated Si wafer. We used the conventional method of APTES deposition i.e., the immersion of an Si wafer in the APTES/methanol 
solution with subsequent drying. After the first immersion of this substrate in AuNPs colloidal solution, we achieved a certain amount of self-aggregated nanoparticles. Before the second immersion, we modified the AuNPs with 1,6-hexanedithiol (HDT), which by one-SH group attached to the first AuNP and by the opposite-SH to the second AuNP, forming the dimer. HDT represents a class of molecules that is commonly used as a crosslinking agent $[6,7,37,38]$. However, so far, it has not been sufficiently studied how well dithiols cover the curved surface of AuNPs, in particular their facets. On flat $\mathrm{Au}(111)$ surfaces, the length of the molecules can determine the structure of the formed self-assembled monolayer [39]. Therefore, we chose shorter HDT molecules, instead of longer NDT being used in earlier studies [20], to minimize the possibility of molecules lying flat on the surface with both -SH terminal groups on the same AuNP.

We studied the influence of the morphology of the molecular layer on the plasmon resonance excitation mechanisms and their polarization properties in assemblies using Fourier-Transform Infrared Spectroscopy (FTIR), UV-vis near-infrared spectroscopy, and modulation-polarization spectroscopy (modulation polarimetry) $[40,41]$.

\section{Materials and Methods}

Formation of AuNPs dimers was performed following the procedure described in detail in [20]. In brief, Si wafers with native oxide and pre-coated with APTES (Merck, USA) were immersed into a water colloidal suspension of AuNPs for $30 \mathrm{~min}$ (in the following labeled as S30). Next, the wafer was first immersed in a solution of HDT (Merck, USA), then in the suspension of AuNPs for 20 min (sample name S30/20). The water-colloidal solution of AuNPs was prepared following the Turkevich protocol [21]. In the solution, all AuNPs were stabilized with trisodium citrate (further on abbreviated as citrate). The citrate molecules prevent AuNPs from self-agglomeration in water. The UV-vis spectra of the AuNP solution showed only one absorption band with $\lambda_{\max }=520 \mathrm{~nm}$, which corresponded to the LSPR band of single colloidal AuNPs of $17 \mathrm{~nm}$ diameter (see Figure S1 in the Supplementary Materials). No sign of agglomeration in the solution was detected.

We performed scanning electron microscopy (SEM) of the Si wafers with assembled AuNPs using a Gemini SEM (Zeiss, Germany). The wafers were attached to the sample holder using conductive double-sided graphite tape. The acceleration voltage was $3 \mathrm{kV}$. The AFM characterization of the wafers covered with AuNPs was done using a Bruker Multimode apparatus operating in the PeakForce ${ }^{\circledR}$ mode in ambient conditions. The radius of the silicon cantilever (RTESPAW-300, Bruker, Germany) was $12 \mathrm{~nm}$.

The XRD and the XRR studies were carried out using a PANalytical X'Pert Pro MRD XL ( $X^{\prime}$ Pert, PANalytical B.V., Almelo, The Netherlands) equipped with a CuK $\alpha$ source of radiation $(\lambda=0.15406 \mathrm{~nm})$. For the determination of the structural properties and phase composition of the films (Figure S2 in the Supplementary Materials) a W/Si parabolic mirror was used to create a high-intensity parallel beam. The diffracted beam was collimated by a parallel plate collimator with an acceptance angle $0.27^{\circ}$, used in combination with a 0.04 rad Soller slit. A four-bounce Ge(220) monochromator and $0.1 \times 10 \mathrm{~mm}$ incident beam collimator were used for the XRR measurements. The diffracted beam was collimated by a parallel plate collimator with an acceptance angle $0.27^{\circ}$, used in combination with a $0.1 \mathrm{~mm}$ receiving slit (collimator slit). Such a combined X-ray investigation provided information about the composition, thickness, density, and roughness of the layer.

FTIR spectra of samples were recorded by a Perkin Elmer Spectrum One spectrometer in the frequency range $400-4000 \mathrm{~cm}^{-1}$. Reflection measurements were carried out using a single beam spectrometer UV-vis SpectraScan (ScanSci, Vila Nova de Gaia, Portugal). Specular reflectance spectra were recorded at an incidence angle of $45^{\circ}$ for unpolarized light. An aluminum mirror was used as the calibration standard (Figure S3 in the Supplementary Materials). Modulation polarimetry was measured of the Q- and V-component of a Stokes vector in geometry external reflection at a $45^{\circ}$ incident angle within the wavelength range $\lambda=400-1000 \mathrm{~nm}$. The parameter $\rho$ is a $Q$-component [42] that characterizes amplitude anisotropy of the interaction with light. The registered signal is the 
polarization difference $\rho(\lambda)=R_{\mathrm{s}}-R_{\mathrm{p}}$ [42-44]. $R_{\mathrm{s}}$ and $R_{\mathrm{p}}$ are the spectra of reflectance for s-polarized and p-polarized light, respectively.

\section{Results and Discussions}

\subsection{Morphology Characterization}

\subsubsection{Atomic Force Microscope (AFM)}

AFM revealed that the surface of $\mathbf{S 3 0}$ and $\mathbf{S 3 0 / 2 0}$ samples was covered mainly with single AuNPs homogeneously dispersed on the substrates (Figure 1). The average height (diameter) of AuNPs amounted to about $17 \mathrm{~nm}$ (Figure 1c). In addition to the single AuNPs, both samples contained aggregates with different sizes, shapes, and surface densities. Their density for $\mathbf{S 3 0}$ was much lower than for S30/20. The average AuNP heights for $\mathbf{S} 30$ did not exceed $30 \mathrm{~nm}$, while for $\mathbf{S 3 0 / 2 0}$ some were higher than $50 \mathrm{~nm}$, as apparent from the cross-section along A-B (Figure 1c,d). Taking into account the average diameter of the AuNPs, we concluded that aggregates for $\mathbf{S} 3 \mathbf{0}$ are formed by two layers of AuNPs while on S30/20 they may be formed by even three layers (Figure 1c). Distinguishing the internal structure of dimers and aggregates was not possible by AFM. Therefore, we performed in addition SEM studies.

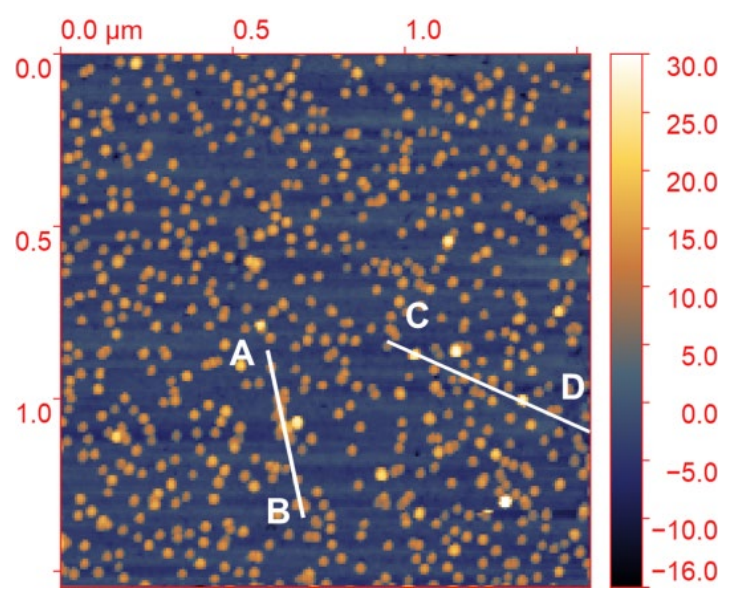

(a)

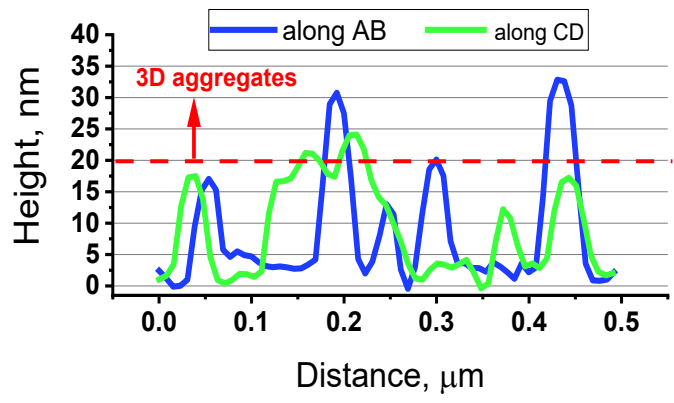

(c)

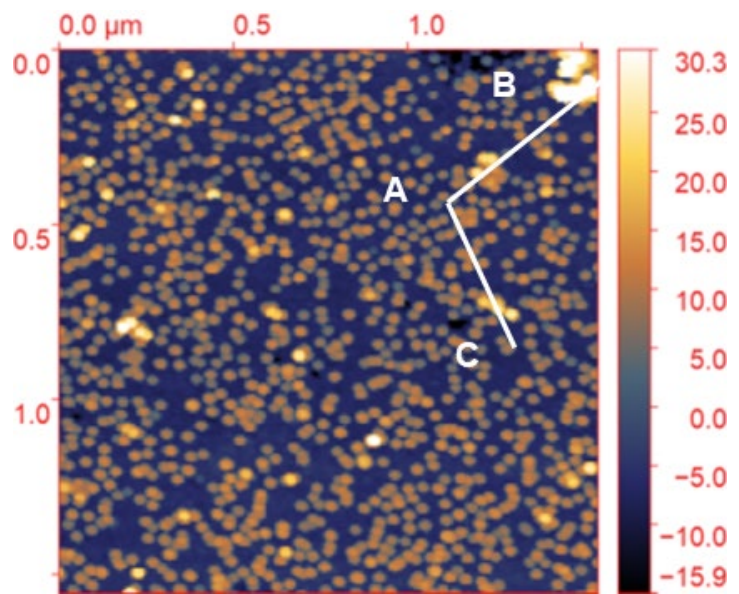

(b)

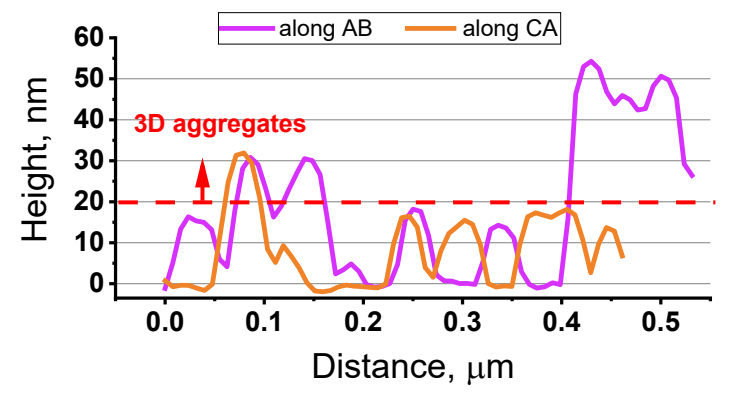

(d)

Figure 1. AFM images $\left(1.54 \times 1.54 \mu \mathrm{m}^{2}\right)$ of the Si wafer surface of (a) S30 and (b) S30/20 with corresponding profiles of cross-sections along A-B, C-D shown in (c) and along A-B-C shown in (d). Each single round spot with a similar color profile corresponds to a single AuNP, while not-uniform objects or the ones with brighter contrast correspond to AuNP aggregates. 


\subsubsection{Scanning Electron Microscopy}

The morphology of the assembly after the first processing step (S30) was characterized by arbitrarily located AuNPs on the Si wafer, as evidenced by SEM (Figure 2a). The majority of the nanoparticles were separated from each other to the distance of at least one nanoparticle diameter, which is explained by the presence of charged shells consisting of citrate molecules during the AuNP synthesis.

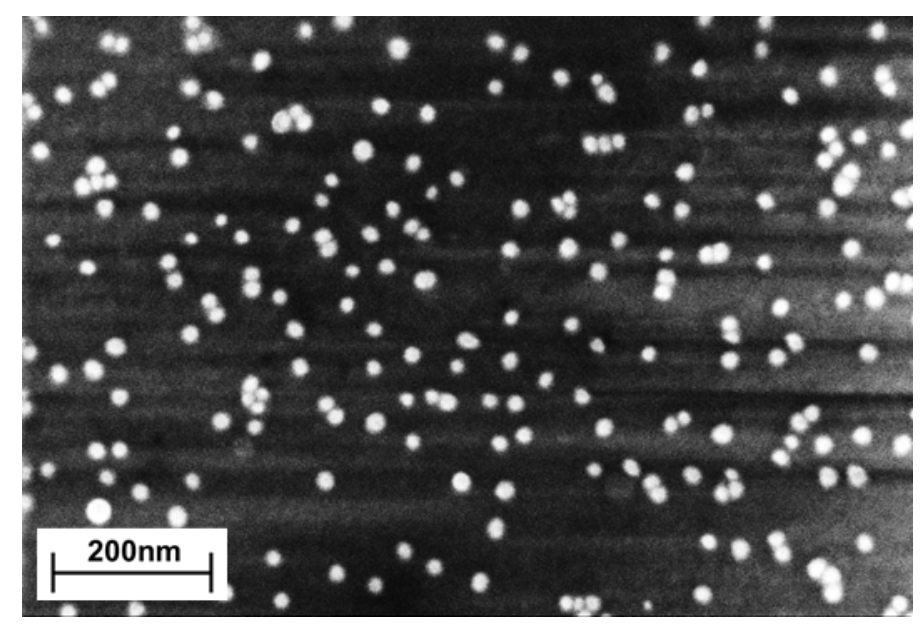

(a)
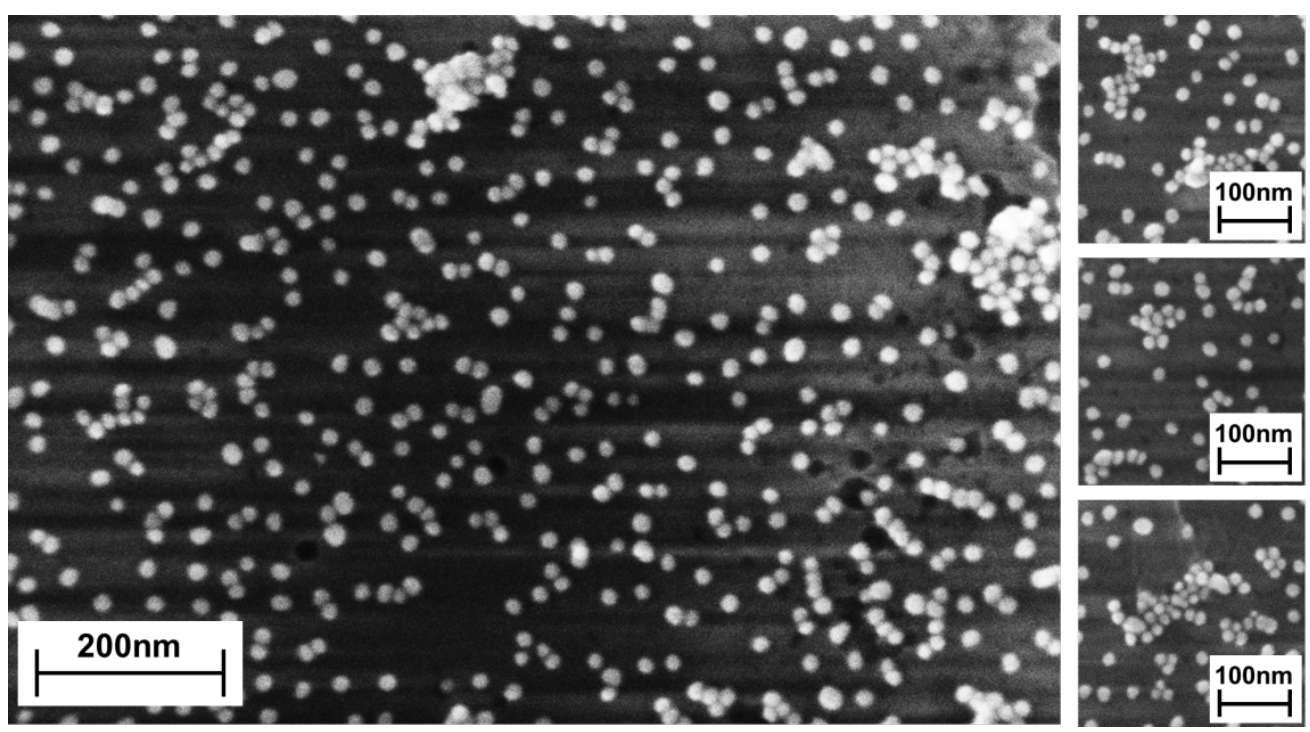

(b)

Figure 2. SEM images of (a) sample S30 and (b) S30/20. The small panels on the right of (b) show further areas of sample S30/20 with large aggregates.

In addition to single AuNPs, some of them were self-organized in aggregates. The smallest were dimers (Figure 2a and Table 1). Larger aggregates contained from three to five nanoparticles self-assembled in lines or in nonlinear groups. The nature of the formation of aggregates on the APTES-coated surface can be explained in the following manner: The aggregation process occurs when AuNPs attach to the surface, since before that, all AuNPs exist as monomers in the colloidal solution, as proven by the absorption spectrum revealing just the single-particle plasmon peak at $520 \mathrm{~nm}$. In the case of a glass surface, the aggregation effect is enhanced with the intrinsic roughness of the surface, which affects the quality of the APTES coating [20]. Therefore, when AuNPs attach to the regions with 
low quality of APTES coatings, a partial replacement of their citrate shells leads to the appearance of electrostatic (dipole-dipole) attraction between them. Our explanation correlates with the earlier observation that a partial replacement of citrate shells by thiols led to the formation of AuNP chains in solution [13]. Fifteen hours immersion of the APTES coated silicon surface in AuNP colloidal solution did neither lead to enlargement of the aggregates nor to a strong rise of their number (Supplementary Materials Figure S4a).

Table 1. Statistical data obtained from the SEM images Figure 2a,b.

\begin{tabular}{cccc}
\hline Types of Nanoobjects & Sample S30, per $\mathbf{1} \boldsymbol{\mu m}^{\mathbf{2}}$ & Sample S30/20, per $\mathbf{1} \boldsymbol{\mu m}^{\mathbf{2}}$ & Increase Rate, $\%$ \\
\hline Monomers & 172 & 291 & 69 \\
Dimers & 16 & 45 & 180 \\
Agglomerates & 8 & 49 & 512 \\
\hline
\end{tabular}

After the treatment of S30 with HDT and immersion in the AuNP colloidal solution to give S30/20, the surface composition changed markedly. The number of single AuNPs increased by $69 \%$, from 172 (S30) to 291 (S30/20) AuNP/ $/ \mathrm{m}^{2}$ (Table 1). The number of dimers almost doubled while the number of aggregates increased by a factor of five. In addition to the small aggregates made of three to five units in S30, much larger aggregates appeared in S30/20 (Figure 2b). The SEM study of the S30/20 surface (2 $\times 2 \mu \mathrm{m}^{2}$ in size) revealed that these large aggregates are composed of 10 to 40 AuNPs.

The comparison of the surface morphology of S30 and S30/20 (Table 1) suggests that one out of five large aggregates of $\mathbf{S 3 0 / 2 0}$ may have originated from the initially formed aggregates of S30, so-called seeds. The other (second) type of seeds, which can also lead to AuNP aggregation, might have appeared during the moment of HDT contact with sample S30. We rationalize this as follows: During the first moment of HDT attachment, HDT molecules attack the surface of AuNPs, which is covered with negatively charged citrate molecules. Partial functionalization of AuNPs leads to a redistribution of AuNP surface charges and the appearance of uncompensated dipole moments. Therefore, if the AuNPs are close enough to each other before contact with HDT, they move towards each other, thereby forming aggregates by dipolar forces. This mechanism is responsible for AuNP chain formation in a colloidal solution [13]. This hypothesis is supported by the presence of elongated aggregates made up of four to seven AuNPs (Figure 2b) that were not detected before the addition of HDT (Figure 2a). Moreover, the majority of large extended aggregates (Figure 2b-right) had mainly a 2D structure with no or only very few AuNPs on top, as is apparent by AFM (Figure 1). This observation suggests that the process of assembly occurs mainly in the vicinity or particularly on the surface. Keeping in mind that AuNPs are anchored to the surface by static interactions of their negatively charged citrate shell and positively charged $-\mathrm{NH}_{3}{ }^{+}$terminal groups of APTES, we do not exclude that they can "slide" over the surface in the presence of stronger dipole-dipole interactions. If this happens, one can expect that around large aggregates possessing strong, attractive forces, the surface density of single AuNPs should be diminished. This assumption is supported by the appearance of a large aggregates with the very low density of single AuNPs in their vicinity. This can even be observed by naked-eye (Figure S4b in the Supplementary Materials).

\subsubsection{X-Ray Reflectivity (XRR)}

X-ray reflectivity analysis allowed the determination of the morphology, including thickness and roughness of the AuNP assembly on the entire Si wafer surface (Figure 3). The XRR of S30 contained periodic intensity oscillations from which the thickness of an ensemble of nanoparticles could be determined. As can be seen from Figure 3, the attenuation rates of the curves for S30 and S30/20 were different, which carry information about the roughness. Thus, a rapid damping of oscillations (or their absence) and a substantial decrease in intensity indicated a significant roughness and, conversely, a weaker attenuation of the intensity indicated a small roughness. 


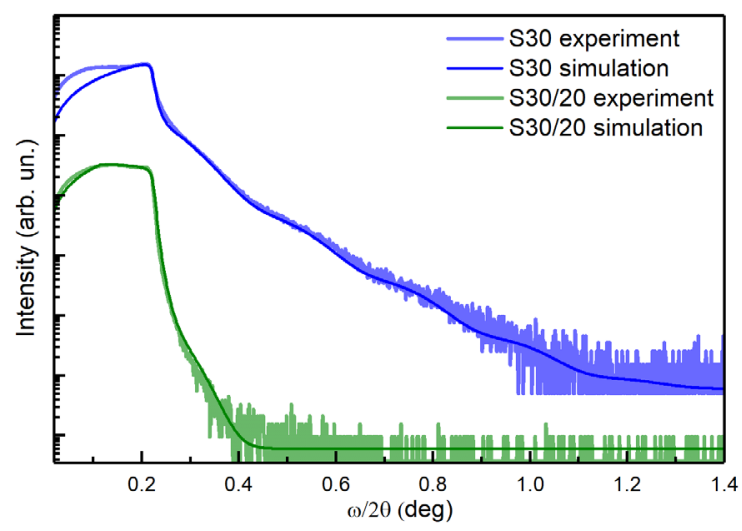

Figure 3. The XRR data obtained for sample $\mathbf{S} 30$ with the inclusion of a small number of self-aggregated AuNPs and for sample S30/20. The experimental data were fitted with the X'Pert Reflectivity software package based on the Parratt formalism [45].

Both spectra were fitted with the X'Pert Reflectivity software package based on the Parratt formalism [45]. The main fitting parameters were the concentration of gold in the composite layer $(x)$, thickness, and roughness of the composite layer $(d$ and $\sigma)$. The concentration of gold directly correlates with the average density of the composite layer, which is determined by the critical angle.

$$
\theta_{c r}=\sqrt{\frac{\lambda^{2} r_{e l}}{\pi} \rho_{e l}}
$$

where $r_{e l}$ is the classical radius of the electron, $\rho_{e l}$ is the average electron density, and $\lambda$ is the wavelength of the X-rays.

We used a model of a thick Si wafer and a thin composite layer $(\mathrm{Au})_{x}(\mathrm{HDT})_{1-x}$ to perform the spectra fitting. We used a single-layer model for S30 and a two-layer model for the S30/20 (for parameters see Table 2). The thickness of $\mathbf{S} 30$ resulting from the fit agreed well with the average diameter of the AuNPs measured with SEM, AFM, and TEM (see Figure S1b in the Supplementary Materials). Therefore, we concluded that the chosen fitting approach using a two-layer model is suitable to study the morphology of $\mathbf{S} 30 / 20$.

Table 2. Parameters of the samples measured with XRR.

\begin{tabular}{ccccc}
\hline Sample & $\rho, \mathbf{g} / \mathbf{c m}^{\mathbf{3}}$ & Au, $\%$ vol. & Thickness d, $\mathbf{n m}$ & Roughness $\sigma, \mathbf{n m}$ \\
\hline S30 & 1 layer: 2.08 & $6 \pm 1$ & $18 \pm 2$ & $1.3 \pm 0.1$ \\
\hline \multirow{2}{*}{ S30/20 } & 1 layer: 1.17 & $1 \pm 1$ & - & $5 \pm 1$ \\
& 2 layer: 2.19 & $6.6 \pm 1$ & - & \\
\hline
\end{tabular}

Further fitting of the spectrum revealed (Figure 3) that the density of the upper layer of S30/20 was significantly lower compared with the bottom layer. The size $(\sim 5 \mathrm{~nm})$ of the layer roughness suggested that the number of 3D objects, which included aggregates and dimerized AuNPs with the orientation outward from the surface, was relatively low.

\subsubsection{Reciprocal Space Maps (RSM)}

For comparing the morphology of $\mathbf{S 3 0}$ and $\mathbf{S 3 0 / 2 0}$ and for studying their influence on the diffuse $\mathrm{X}$-ray scattering component, an intensity mapping using reciprocal space maps (RSMs) around the (000) reciprocal lattice point was measured.

The specular XRR profile (Figure 3) corresponded to the line on the RSM along the $q_{z}$ direction, for $q_{x}=0$. The diffuse scattering components $\left(q_{x} \neq 0\right)$ were attributed to the roughness and to the lateral 
and vertical correlation lengths. A series of $\omega / 2 \theta$ XRR scans at different incidence angles of X-rays was measured.

The reciprocal space map is the distribution of the intensity of the scattered X-rays as a function of coordinates in the reciprocal space, which are given by the following relations:

$$
\begin{aligned}
& q_{x}=(\cos (\omega)-\cos (2 \theta-\omega)) / \lambda \\
& q_{z}=(\sin (\omega)+\sin (2 \theta-\omega)) / \lambda
\end{aligned}
$$

where $\omega$ is the incidence angle, $2 \theta-\omega$ is the scattering angle, $\lambda$ is the wavelength of the X-rays, and $z$ and $x$ correspond to the axial directions along the normal and parallel to the surface, respectively.

The diffuse scattering mechanism is sketched in Figure 4.
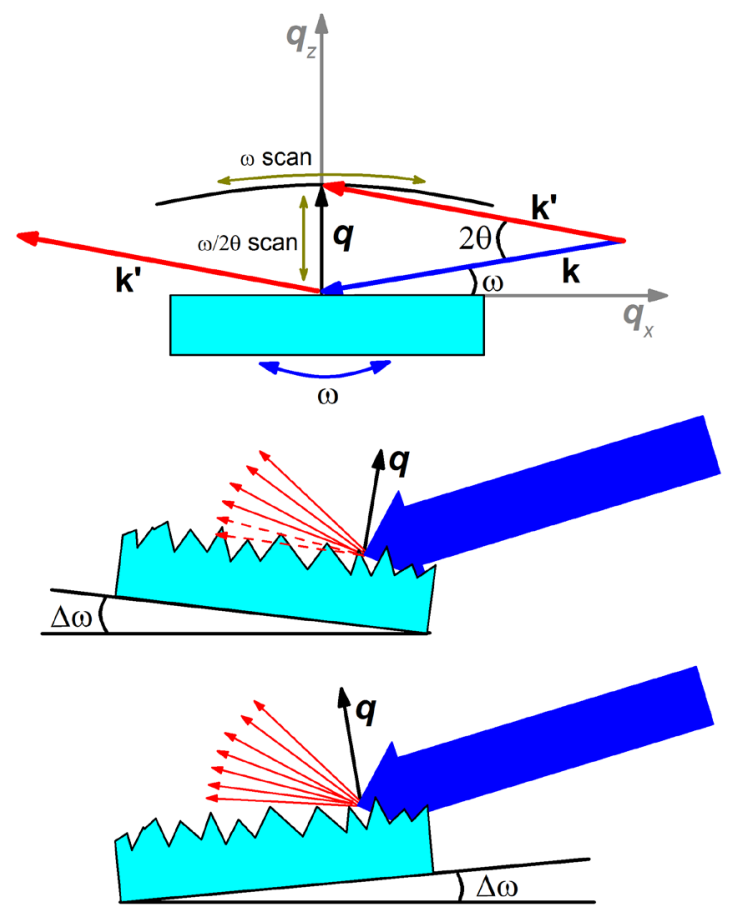

Figure 4. Schematic diagram of RSM measuring and formation scheme of diffuse scattering at different incidence angles of $\mathrm{X}$-rays.

A significant contribution of the specular scattering component, manifested by a relatively high intensity along the $q_{z}$ direction at $q_{x}=0$, was observed for S30. This confirms our above observations about the low surface roughness of S30. For S30/20, practically all the incident intensities were scattered without a specular contribution to the RSM. Almost the entire intensity of the incident X-ray irradiation was scattered off surface inhomogeneities. This fact and the asymmetry of the diffuse scattering (Figure 5b) evidenced the presence of enhanced roughness in S30/20. Thus, the RSM indicated the absence of a vertical correlation of the roughness profiles [46], which suggested that all 3D objects in S30/20, including dimers and larger aggregates of AuNPs, were randomly distributed on the surface and did not have any particular orientation with respect to the surface. 


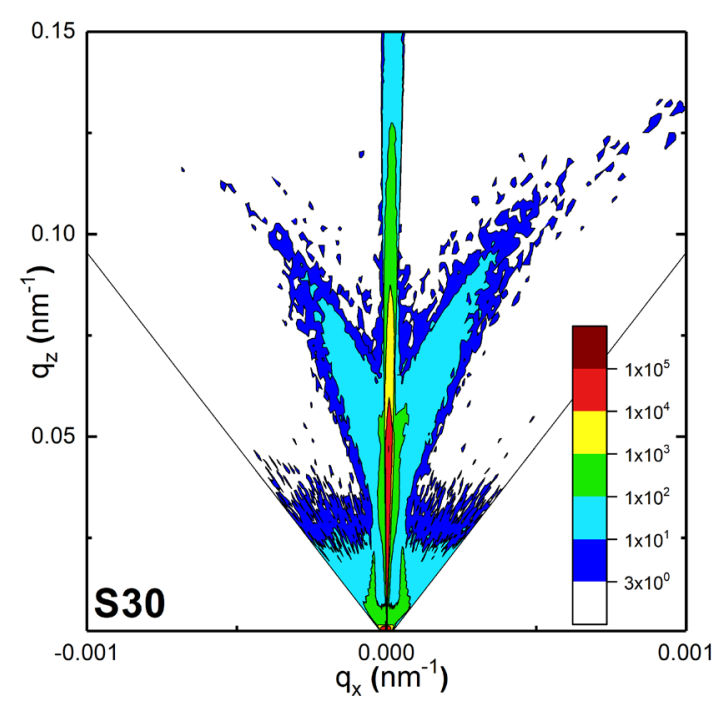

(a)

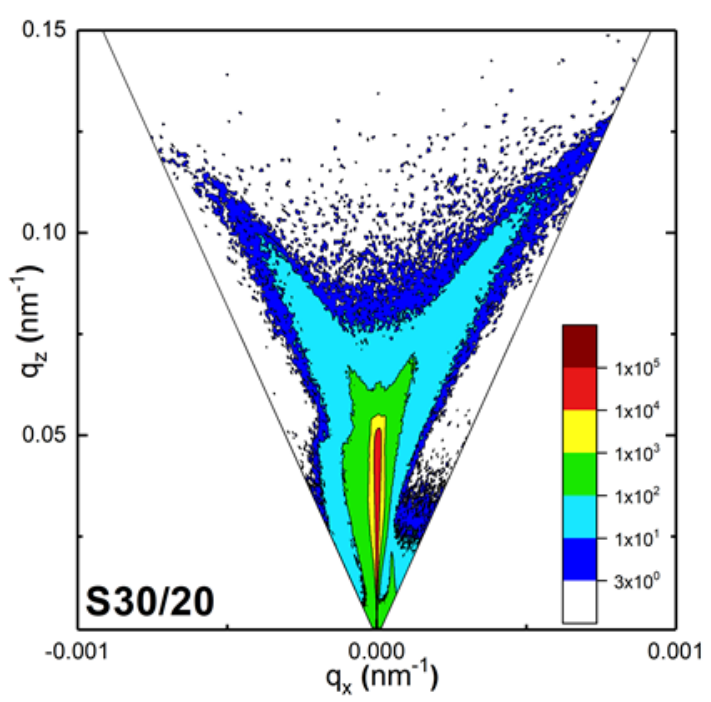

(b)

Figure 5. The experimental reciprocal space maps for (a) sample S30 and (b) S30/20.

\subsection{Optical Characteristics of SAMs}

\subsubsection{Fourier-Transform Infrared Spectroscopy (FTIR)}

The presence of organic layers on the Si wafer and the AuNPs was confirmed by FTIR spectroscopy measurements (Figure 6). For S30 and S30/20, particularly intensive absorption at $620 \mathrm{~cm}^{-1}$ corresponded to vibrations of $\mathrm{Si}-\mathrm{Si}$ bonds in the Si wafer. The presence of APTES in both samples stipulated identical bands in IR spectra at 410 and $460 \mathrm{~cm}^{-1}$, which are assigned to deformational vibrations of the Si-O-Si group [47]. Similarly, a sharp peak at $1115 \mathrm{~cm}^{-1}$ was attributed to asymmetric valence vibrations of the Si-O-Si group. Two pronounced bands at 744 and $890 \mathrm{~cm}^{-1}$ in both spectra were attributed to the rocking vibration of $\mathrm{C}-\mathrm{H}$ bonds in the APTES layer. The amino groups caused a band at the intermediate wavenumber of $975 \mathrm{~cm}^{-1}$ corresponding to the rocking vibration of the $\mathrm{N}-\mathrm{H}$ bond, and two weak bands at 1560 and $1515 \mathrm{~cm}^{-1}$ were attributed to the bending vibration of $\mathrm{N}-\mathrm{H}$. A series of weak vibrations in the range $1300-1450 \mathrm{~cm}^{-1}$ were attributed to deformation vibrations in $\mathrm{C}-\mathrm{H}$ and $\mathrm{O}-\mathrm{H}$ groups [48].

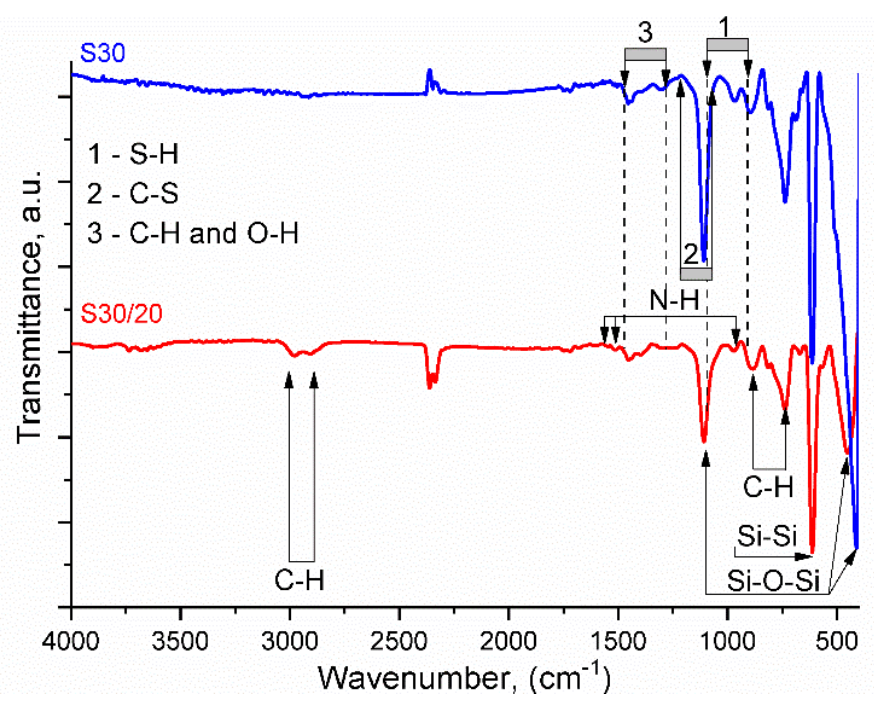

Figure 6. FTIR data for S30 with a single AuNP layer with inclusion of minor number of self-aggregated nanoparticles in comparison S30/20). 
The overlapping of weak vibration of S-H bonds in the fingerprint range $900-1100 \mathrm{~cm}^{-1}$ as well as the overlap of vibrations of C-S bonds in the range 1200-1050 $\mathrm{cm}^{-1}$ were registered for S30/20 with APTES and HDT organic components. However, two peaks at 2912 and $2994 \mathrm{~cm}^{-1}$ were typical of $\mathrm{C}-\mathrm{H}$ stretching vibrations and indicate the HDT presence $[48,49]$.

\subsubsection{Specular Reflectance of Non-Polarized Light}

Figure 7 shows the specular reflectance spectra for samples S30 and S30/20. The main difference between the spectra was their amplitude, which amounted to about $12 \%$ for sample S30 and $8 \%$ for sample S30/20. Single, dimer, and more complex forms of AuNP aggregates were detected on Si wafers for S30 and S30/20 using AFM and SEM (Figures 1 and 2). Therefore, it might have been expected that the light reflection spectra of non-polarized light would reveal unique distinguishable spectral characteristics for each type of nanoobjects on studied Si wafers. However, we observed a relatively low level of reflectance for both samples with a distinguishable difference of the amplitude for S30 and S30/20 (Figure 7). Such low reflectance could be associated with the resonant interaction of light with an array of NP, which was additionally reinforced by the light scattering effect (antireflective effects) [50]. Therefore, the amplitude of reflectance for S30/20 was about $4 \%$ lower compared to S30, since light absorption and scattering increased for S30/20 because of the higher surface density of AuNP compared to S30 [51,52].

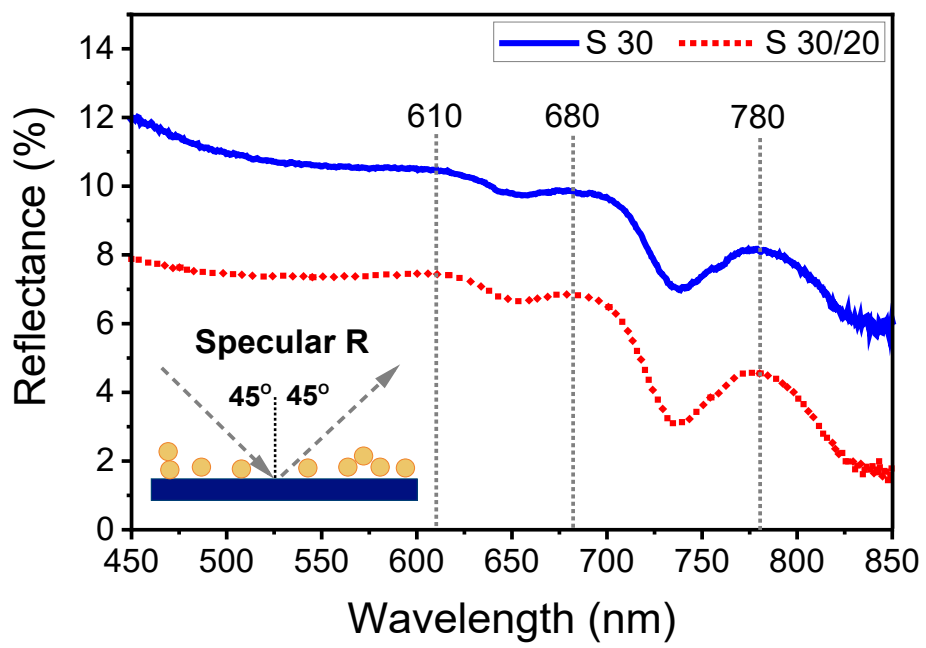

Figure 7. Optical reflectance spectra for sample S30 (solid blue curve) and S30/20 (red dotted curve). The incidence angle was $45^{\circ}$.

Furthermore, the spectra revealed several shallow and broad maxima and minima in the spectral range between 600 and $850 \mathrm{~nm}$ at very similar wavelength for both samples. To interpret these observations, we had to consider that several mechanisms, including absorption and scattering, determine the spectral dependence of the reflectance spectra of nanosystems on opaque substrates. [50,53,54]. Depending on the relative contribution of scattering an absorption, maxima as well as minima may occur at the wavelength corresponding to plasmonic excitations. The contribution of scattering effects increases with increasing size and configuration of aggregates consisting of different numbers of single nanoparticles [53]. As a consequence, in the present measurement, the maxima in the reflectance spectra were associated with back-scattered light and LSPR dipolar mode excitation of NP arrays [50]. The minima in the spectra could be associated with the excitation of higher multipole modes (quadrupolar) and forward-scattered light [50].

The profiles of the reflectance spectra of both samples were rather similarly corresponding to the similar composition of $\mathbf{S 3 0}$ and S30/20, i.e., both samples contained monomeric AuNPs, dimers, and aggregates with multiple forms (Figures 1 and 2). It might have been expected that 3D aggregates of 
S30/20 would give more impact on the resulting spectrum. However, as it was shown for multilayered AuNP assemblies, some of the plasmon modes can vanish [55].

The LSPR for single AuNPs was expected near $520 \mathrm{~nm}$ [56], since the absorption spectra of our colloidal AuNPs exhibited a peak at $520 \mathrm{~nm}$ in solution (Figure S1 in the Supplementary Materials). The position of the LSPR may have been slightly shifted due to the difference in the dielectric constant of water $(\varepsilon=1.77)$ and air $(\varepsilon=1)$, when single AuNPs were deposited on glass and measured in transmission in air [20,56]. Therefore, on the Si wafer in the reflection geometry, the position of the LSPR also may slightly vary. However, there was no indication of a peak around 520nm on any of the samples, despite their presence on the surface, as revealed by SEM (Figure 2). The absence of such characteristic peak may have several reasons. At first, for aggregates consisting of individual spheres and arrays, simultaneously the dipolar and quadrupolar modes may be excited and interfere in the scattered light [57]. As a result, the spectral contours of these modes may overlap and eventually cancel. Additionally, according to [58,59], interband transitions of AuNPs affect the shape of the LSPR spectrum. All features of specular reflectance spectra for $\mathbf{S 3 0}$ and S30/20 are related to simultaneous resonant interaction between the single NPs and various forms of aggregates with electromagnetic radiation. Mainly, such an interaction takes place between single AuNPs interconnected in dimers with larger aggregates and different interparticle distances, as were detected by morphological investigations. The electromagnetic fields related to the LSPR mode of one NP may then influence the response of neighboring nanoparticles. This electromagnetic coupling can take several forms: via near-fields and via far-fields [60]. Particles can interact via near-field coupling when they are relatively densely packed, leading to significant spectral shifts of the plasmon resonances and modification and splitting of their line-shapes due to the hybridization of the plasmon modes.

Variations of the reflectance become more apparent with increasing the size and configuration of nanoobjects, since the level of hybridization of plasmon modes of interconnected AuNP increases [61,62]. We attributed the broad band around $610 \mathrm{~nm}$ to the reflectance of dimers and had two main origins. It may have appeared as the result of the coupled dipole oscillation of the longitudinal optical excitation mode along the dimer axis between the two nanoparticles [31]. At the same time, the dipole-dipole interactions within AuNP agglomerates may have given an additional impact on the formation of the maximum [61]. Both of these types of coupling create new collective oscillation modes. Besides, S30/20 may have contained two types of dimers. The first one appeared due to self-aggregation during the first immersion, while the second one was interconnected via HDT. Consequently, instead of a single narrow reflection mode [31], we observed a broad hill at around $610 \mathrm{~nm}$. Similarly, the maxima around 680 and $780 \mathrm{~nm}$ could be attributed to hybridization modes of trimers and more complex objects, e.g., chains $[62,63]$ based on the same mechanisms as the dipole mode.

As mentioned above, also the minima may reflect plasmon excitations, in particular if the absorption dominates over the scattering contribution. We therefore tentatively attribute the minima around $660 \mathrm{~nm}$ and $730 \mathrm{~nm}$ as quadrupular modes of dimers and trimers, respectively.

\subsubsection{Modulation Polarimetry}

The spectral characteristics of $Q$ - and $V$-components of the Stokes vector were measured to reveal polarization-dependent amplitude and phase anisotropy effects in the external reflection for plasmonic NP arrays (Figure 8). We used a method based on recording the amplitude difference in the reflectance intensity between $s$ - and $p$-polarized beams, which suppressed the common-mode noise. The registration signal of the $Q$ component of the Stokes vector is larger and more informative than that of the method of interaction with only p-polarized light [20].

The $Q$-component takes into account the simultaneous interaction with $s$ - and $p$-polarized electromagnetic radiation. The $Q$-component is determined by the linear (amplitude) anisotropy since it is equal to the difference between the reflectance of $R_{\mathrm{s}}$ and $R_{\mathrm{p}}$. The decrease of the spectral amplitude of $Q(\lambda)$ for $\mathbf{S 3 0 / 2 0}$ was related to an increase of nanoparticle concentration and a resonance interaction with electromagnetic radiation $[42,64]$ (Figure 8a). 


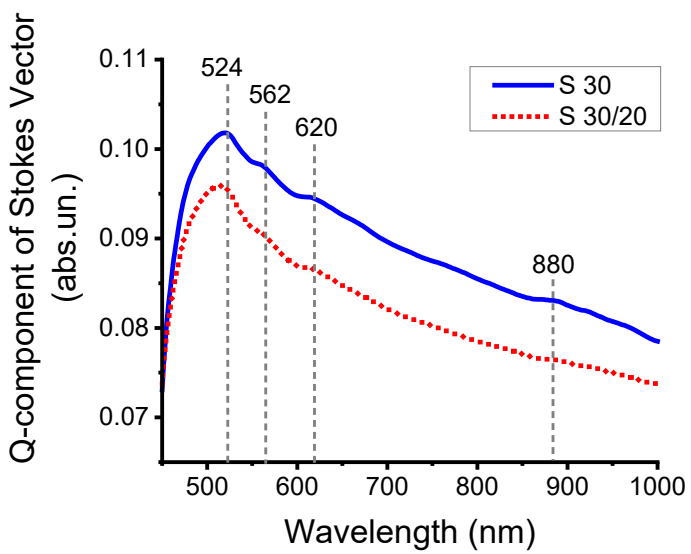

(a)

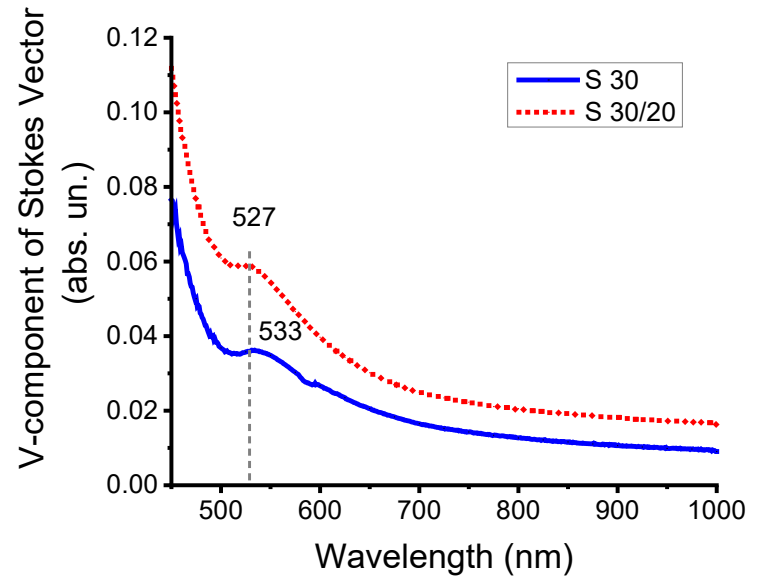

(b)

Figure 8. The modulation polarimetry spectra for samples S30 and S30/20: (a) amplitude and (b) phase anisotropy.

The observed spectral characteristics for plasmonic nanoparticle arrays originate from the differential excitation of the two orthogonal dipolar plasmon resonances (transverse and longitudinal) by orthogonal linear polarization [65]. For oblique incidence of light of both s- and p-polarizations on nanoparticle arrays, the in-plane and out-of-plane resonances that characterize excitations of plasmon oscillations in the plane of the array and perpendicular to the array plane are excited [66]. In this case, the polarization-dependent light interaction with the NP array leads to hybridization between parallel and orthogonal surface lattice resonances [67].

Additionally, for disordered arrays, the broken symmetry could lead to the in-plane excitation of a quadrupolar mode and a change of extinction or reflectance [68]. The parameter $V(\lambda)$ is determined by the circular (phase) anisotropy, since it contains the phase difference between orthogonal polarization states, $s$ - and $p$-, correspondently [69]. The spectral characteristics of the $V$-component of the Stokes vector, on the other hand, characterize the resulting phase between the competing dipolar or hybridized plasmon modes [65].

The features of $V(\lambda)$ for $\mathbf{S} 30$ and $\mathbf{S 3 0 / 2 0}$ in the $500-620 \mathrm{~nm}$ spectral range are related to the LSPR and has a maximum at $527 / 533 \mathrm{~nm}$ since the rotation of the polarization state in circular anisotropy is always sensitive to the localization of light and LSPR [70].

An increase in the number of particles of various shapes on the surface of silicon wafers leads to a decrease in the amplitude of the components of the Stokes vector ( $Q$ and $V$ ) of reflected light due to the excitation of localized plasmon resonance. Monomers, dimers, trimers, and aggregates contribute to this integral change in the amplitude of the components of the Stokes vector.

\section{Conclusions}

The combination of X-ray techniques, modulation polarimetry, FTIR, AFM, and SEM methods allowed an in-depth analysis of the morphology of sophisticated organometallic coatings made of AuNPs cross-linked with 1,6-hexanedithiol molecules directly on a silicon wafer. We found that the AuNP dimers were formed not only through the dithiol molecules, as expected, but could appear as a result of self-aggregation directly on the APTES-coated wafer surface. For distinguishing the difference in optical signals from self-aggregated dimers and the ones formed through dithiols, further studies are necessary.

In addition to the self-dimerized AuNPs, aggregates with non-uniform shapes were detected. The small lateral size of these aggregates, after the first incubation of the APTES-coated wafer in the colloidal solution, suggests that they can appear due to local defects in the APTES coating. The second incubation led to their significant enlarging. Meantime, the number of dimers remained rather low. 
These observations suggest that aggregates on the surface attract NPs from the solution more efficiently than the single NPs. The nature of the force that drives this aggregation could not be revealed evidently yet. One possibility could be a net dipole moment of the aggregates, which may attract citrate-coated AuNP from the solution more efficiently than single AuNPs.

Despite the presence of aggregates during both stages of precipitation, the polarized light spectroscopy revealed a strong signal from AuNP dimers. The feasibility of modulation-polarization spectroscopy for the detection of plasmonic modes for the single, dimer, and larger aggregates of NPs was illustrated for the simple plasmonic system of an AuNp assembly.

Supplementary Materials: The following are available online at http://www.mdpi.com/2079-4991/10/3/512/s1, Figure S1 UV-vis spectrum and analysis of AuNPs, Figure S2: XRD patterns of the samples S30 and S30/20, Figure S3: Reflectance spectrum of Al mirror, Figure S4: SEM images of control samples.

Author Contributions: Conceptualization, M.S. and S.S.; Data curation, M.S., A.H., and S.F.; Formal analysis, T.M.; Funding acquisition, B.L. and J.Q.; Methodology, M.S., S.K., and L.M.; Supervision, B.L. and J.Q.; Writing-original draft, S.S., M.S.; Writing-review and editing, E.S. and S.S. All authors have read and agreed to the published version of the manuscript.

Funding: This work has been partially supported by the National Natural Science Foundation of China (61604098, 61835009), the Shenzhen Basic Research Project (JCYJ20170412110137562, JCYJ20170302143001451, JCYJ20170412105003520), the Shenzhen University Research Start-up Foundation (860-000002110207) and also by the Key Project of Science and Technology of Guangdong Province (Grant No. 2020B010169003), the DFG through the joint DFG-ANR project PlasmoChrom, and through SFB 1214.

Acknowledgments: The authors are grateful to V. Lytvyn (V. Lashkaryov Institute of Semiconductor Physics, National Academy of Sciences of Ukraine) for fruitful discussion. M. O. Stetsenko thanks the National Academy of Science of Ukraine for a young scientist's scholarship (2017-2019).

Conflicts of Interest: The authors declare no conflict of interest.

\section{References}

1. Cao, L.; Wang, P.; Chen, L.; Wu, Y.; Di, J. A photoelectrochemical glucose sensor based on gold nanoparticles as a mimic enzyme of glucose oxidase. RSC Adv. 2019, 9, 15307-15313. [CrossRef]

2. Zheng, S.; Zhang, H.; Lakshmipriya, T.; Gopinath, S.C.B.; Yang, N. Gold nanorod integrated electrochemical sensing for hyperglycaemia on interdigitated electrode. BioMed Res. Int. 2019, 2019, 9726967. [CrossRef]

3. Huang, J.; Zhang, Y.; Lin, Z.; Liu, W.; Chen, X.; Liu, Y.; Tian, H.; Liu, Q.; Gillibert, R.; Spadavecchia, J.; et al. Femtomolar detection of nucleic acid based on functionalized gold nanoparticles. Nanophotonics 2019, 8, 1495-1503. [CrossRef]

4. Guan, Z.; Zhang, T.; Zhu, H.; Lyu, D.; Sarangapani, S.; Xu, Q.-H.; Lang, M.J. Simultaneous imaging and selective photothermal therapy through aptamer-driven au nanosphere clustering. J. Phys. Chem. Lett. 2019, 10, 183-188. [CrossRef] [PubMed]

5. Chemla, Y.; Betzer, O.; Markus, A.; Farah, N.; Motiei, M.; Popovtzer, R.; Mandel, Y. Gold nanoparticles for multimodal high-resolution imaging of transplanted cells for retinal replacement therapy. Nanomedicine (Lond. U.K.) 2019, 14, 1857-1871. [CrossRef] [PubMed]

6. McCold, C.E.; Fu, Q.; Howe, J.Y.; Hihath, J. Conductance based characterization of structure and hopping site density in 2D molecule-nanoparticle arrays. Nanoscale 2015, 7, 14937-14945. [CrossRef] [PubMed]

7. Tie, M.; Dhirani, A.A. Conductance of molecularly linked gold nanoparticle films across an insulator-to-metal transition: From hopping to strong Coulomb electron-electron interactions and correlations. Phys. Rev. B 2015, 91, 155131. [CrossRef]

8. Lu, F.; Yager, K.G.; Zhang, Y.; Xin, H.; Gang, O. Superlattices assembled through shape-induced directional binding. Nat. Commun. 2015, 6, 6912. [CrossRef]

9. Hofmann, A.; Schmiel, P.; Stein, B.; Graf, C. Controlled formation of gold nanoparticle dimers using multivalent thiol ligands. Langmuir 2011, 27, 15165-15175. [CrossRef]

10. Di, H.; Liu, H.; Li, M.; Li, J.; Liu, D. High-precision profiling of sialic acid expression in cancer cells and tissues using background-free surface-enhanced Raman scattering tags. Anal. Chem. 2017, 89, 5874-5881. [CrossRef] 
11. Song, S.; Kuang, Y.; Luo, L.; Sun, X. Asymmetric hetero-assembly of colloidal nanoparticles through "crash reaction" in a centrifugal field. Dalton Trans. 2014, 43, 5994-5997. [CrossRef] [PubMed]

12. Zhou, H.T.; Zheng, L.Q.; Jia, H. Facile control of the self-assembly of gold nanoparticles by changing the capping agent structures. Colloids Surf. A 2014, 450, 9-14. [CrossRef]

13. Li, M.; Johnson, S.; Guo, H.; Dujardin, E.; Mann, S. A generalized mechanism for ligand-induced dipolar assembly of plasmonic gold nanoparticle chain networks. Adv. Funct. Mater. 2011, 21, 851-859. [CrossRef]

14. Sánchez-Iglesias, A.; Grzelczak, M.; Altantzis, T.; Goris, B.; Pérez-Juste, J.; Bals, S.; Van Tendeloo, G.; Donaldson, S.H.; Chmelka, B.F.; Israelachvili, J.N.; et al. Hydrophobic interactions modulate self-assembly of nanoparticles. ACS Nano 2012, 6, 11059-11065. [CrossRef] [PubMed]

15. Yoon, J.H.; Zhou, Y.; Blaber, M.G.; Schatz, G.C.; Yoon, S. Surface plasmon coupling of compositionally heterogeneous core-satellite nanoassemblies. J. Phys. Chem. Lett. 2013, 4, 1371-1378. [CrossRef] [PubMed]

16. Lermusiaux, L.; Funston, A.M. Plasmonic isomers via DNA-based self-assembly of gold nanoparticles. Nanoscale 2018, 10, 19557-19567. [CrossRef]

17. Kutsenko, V.Y.; Lopatina, Y.Y.; Bossard-Giannesini, L.; Marchenko, O.A.; Pluchery, O.; Snegir, S.V. Alkylthiol self-assembled monolayers on $\mathrm{Au}(111)$ with tailored tail groups for attaching gold nanoparticles. Nanotechnology 2017, 28, 235603-235606. [CrossRef]

18. Kano, S.; Tada, T.; Majima, Y. Nanoparticle characterization based on STM and STS. Chem. Soc. Rev. 2015, 44, 970-987. [CrossRef]

19. Kyaw, H.H.; Al-Harthi, S.H.; Sellai, A.; Dutta, J. Self-organization of gold nanoparticles on silanated surfaces. Beilstein J. Nanotechnol. 2015, 6, 2345-2353. [CrossRef]

20. Stetsenko, M.O.; Rudenko, S.P.; Maksimenko, L.S.; Serdega, B.K.; Pluchery, O.; Snegir, S.V. Optical properties of gold nanoparticle assemblies on a glass surface. Nanoscale Res. Lett. 2017, 12, 348-358. [CrossRef]

21. Snegir, S.; Mukha, I.; Sysoiev, D.; Lacaze, E.; Huhn, T.; Pluchery, O. Optically controlled properties of nanoparticles stabilised by photochromic difurylethene-base diarylethenes. Materialwiss. Werkstofftech. 2016, 47, 229-236. [CrossRef]

22. Abu Bakar, N.; Mat Salleh, M.; Ali Umar, A.; Shapter, J.G. Direct deposition of silver nanoplates on quartz surface by sequence pre-treatment hydroxylation and silanisation. MethodsX 2017, 4, 486-491. [CrossRef] [PubMed]

23. Abu Bakar, N.; Shapter, J.; Mat Salleh, M.; Ali Umar, A. Self-assembly of high density of triangular silver nanoplate films promoted by 3-aminopropyltrimethoxysilane. Appl. Sci. 2015, 5, 209-221. [CrossRef]

24. Cano, M.; de la Cueva-Méndez, G. Self-assembly of a superparamagnetic raspberry-like silica/iron oxide nanocomposite using epoxy-amine coupling chemistry. Chem. Commun. 2015, 51, 3620-3622. [CrossRef] [PubMed]

25. Soliveri, G.; Annunziata, R.; Ardizzone, S.; Cappelletti, G.; Meroni, D. Multiscale rough titania films with patterned hydrophobic/oleophobic features. J. Phys. Chem. C 2012, 116, 26405-26413. [CrossRef]

26. Shakeri, A.; Yip, D.; Badv, M.; Imani, S.M.; Sanjari, M.; Didar, T.F. Self-cleaning ceramic tiles produced via stable coating of $\mathrm{TiO}(2)$ nanoparticles. Materials (Basel) 2018, 11, 1003. [CrossRef]

27. Liu, Y.; Li, Y.; Li, X.M.; He, T. Kinetics of (3-aminopropyl) triethoxylsilane (APTES) silanization of superparamagnetic iron oxide nanoparticles. Langmuir 2013, 29, 15275-15282. [CrossRef]

28. Zhu, N.; Ji, H.; Yu, P.; Niu, J.; Farooq, M.U.; Akram, M.W.; Udego, I.O.; Li, H.; Niu, X. Surface modification of magnetic Iron Oxide nanoparticles. Nanomaterials (Basel) 2018, 8, 810. [CrossRef] [PubMed]

29. Rao, X.; Hassan, A.A.; Guyon, C.; Ognier, S.; Tatoulian, M. Plasma deposited high density amines on surface using (3-aminopropyl) triethoxysilane for assembling particles at near-nano size. Mater. Chem. Phys. 2020, 240, 121974. [CrossRef]

30. Zheng, Y.; Thai, T.; Reineck, P.; Qiu, L.; Guo, Y.; Bach, U. DNA-directed self-assembly of core-satellite plasmonic nanostructures: A highly sensitive and reproducible near-IR SERS sensor. Adv. Funct. Mater. 2013, 23, 1519-1526. [CrossRef]

31. Cha, H.; Yoon, J.H.; Yoon, S. Probing quantum plasmon coupling using gold nanoparticle dimers with tunable interparticle distances down to the subnanometer range. ACS Nano 2014, 8, 8554-8563. [CrossRef]

32. Cha, H.; Lee, D.; Yoon, J.H.; Yoon, S. Plasmon coupling between silver nanoparticles: Transition from the classical to the quantum regime. J. Colloid Interface Sci. 2016, 464, 18-24. [CrossRef] [PubMed] 
33. Klug, J.; Pérez, L.A.; Coronado, E.A.; Lacconi, G.I. Chemical and electrochemical oxidation of silicon surfaces functionalized with APTES: The role of surface roughness in the AuNPs anchoring kinetics. J Phys. Chem. C 2013, 117, 11317-11327. [CrossRef]

34. Yadav, A.R.; Sriram, R.; Carter, J.A.; Miller, B.L. Comparative study of solution-phase and vapor-phase deposition of aminosilanes on silicon dioxide surfaces. Mater. Sci. Eng. C 2014, 35, 283-290. [CrossRef] [PubMed]

35. Pasternack, R.M.; Rivillon Amy, S.; Chabal, Y.J. Attachment of 3-(Aminopropyl) triethoxysilane on silicon Oxide surfaces: Dependence on solution temperature. Langmuir 2008, 24, 12963-12971. [CrossRef] [PubMed]

36. Acres, R.G.; Ellis, A.V.; Alvino, J.; Lenahan, C.E.; Khodakov, D.A.; Metha, G.F.; Andersson, G.G. Molecular structure of 3-aminopropyltriethoxysilane layers formed on silanol-terminated silicon surfaces. J. Phys. Chem. C 2012, 116, 6289-6297. [CrossRef]

37. García Raya, D.; Madueño, R.; Blázquez, M.; Pineda, T. Formation of a 1, 8-octanedithiol self-assembled monolayer on $\mathrm{Au}$ (111) prepared in a lyotropic liquid-crystalline medium. Langmuir 2010, 26, 11790-11796. [CrossRef]

38. Kim, M.; Kwon, H.; Lee, S.; Yoon, S. Effect of nanogap morphology on plasmon coupling. ACS Nano 2019, 13, 12100-12108. [CrossRef]

39. Vericat, C.; Vela, M.E.; Benitez, G.; Carro, P.; Salvarezza, R.C. Self-assembled monolayers of thiols and dithiols on gold: New challenges for a well-known system. Chem. Soc. Rev. 2010, 39, 1805-1834. [CrossRef]

40. Hafezian, S.; Baloukas, B.; Martinu, L. Percolation threshold determination of sputtered silver films using Stokes parameters and in situ conductance measurements. Appl. Opt. 2014, 53, 5367-5374. [CrossRef]

41. Fernández-Blanco, C.; Colina, Á.; Heras, A. UV/Vis spectroelectrochemistry as a tool for monitoring the fabrication of sensors based on silver nanoparticle modified electrodes. Sensors 2013, 13, 5700-5711. [CrossRef]

42. Fiorillo, A.S.; Pullano, S.A.; Rudenko, S.P.; Stetsenko, M.O.; Maksimenko, L.S.; Krishchenko, I.M.; Synyuk, V.S. Antireflection properties of composite zeolite gold nanoparticles film. Electron. Lett. 2018, 54, 370-372. [CrossRef]

43. Stetsenko, M.; Pullano, S.A.; Margitych, T.; Maksimenko, L.; Hassan, A.; Kryvyi, S.; Hu, R.; Huang, C.; Ziniuk, R.; Golovynskyi, S.; et al. Antireflection enhancement by composite nanoporous zeolite 3A-Carbon thin film. Nanomaterials (Basel) 2019, 9, 1641. [CrossRef] [PubMed]

44. Stetsenko, M.O.; Matyash, I.E.; Rudenko, S.P.; Minailova, I.A.; Maksimenko, L.S.; Serdega, B.K. New type of plasmonic biosensors based on modulation polarimetry technique. In Proceedings of the 2017 IEEE International Young Scientists Forum on Applied Physics and Engineering (YSF), Lviv, Ukraine, 17-20 October 2017; pp. 100-103. [CrossRef]

45. Parratt, L.G. Surface studies of solids by total reflection of X-rays. Phys. Rev. 1954, 95, 359-369. [CrossRef]

46. Daillant, J.; Gibaud, A. X-ray and Neutron Reflectivity: Principles and Applications; Springer: Berlin/Heidelberg, Germany, 2009; Volume 770, pp. 1-348. [CrossRef]

47. Rao, X.; Guyon, C.; Ognier, S.; Da Silva, B.; Chu, C.; Tatoulian, M.; Hassan, A.A. High density gold nanoparticles immobilized on surface via plasma deposited APTES film for decomposing organic compounds in microchannels. Appl. Surf. Sci. 2018, 439, 272-281. [CrossRef]

48. Larkin, P. Infrared Raman Spectrosc; Elsevier: Amsterdam, The Netherlands, 2011; p. 230.

49. Chirea, M.; Borges, J.; Pereira, C.M.; Silva, A.F. Density-dependent electrochemical properties of vertically aligned gold nanorods. J. Phys. Chem. C 2010, 114, 9478-9488. [CrossRef]

50. Temple, T.L.; Mahanama, G.D.K.; Reehal, H.S.; Bagnall, D.M. Influence of localized surface plasmon excitation in silver nanoparticles on the performance of silicon solar cells. Sol. Energy Mater. Sol. Cells 2009, 93, 1978-1985. [CrossRef]

51. Yang, S.C.; Kobori, H.; He, C.L.; Lin, M.H.; Chen, H.Y.; Li, C.; Kanehara, M.; Teranishi, T.; Gwo, S. Plasmon hybridization in individual gold nanocrystal dimers: Direct observation of bright and dark modes. Nano Lett. 2010, 10, 632-637. [CrossRef]

52. Huang, Y.; Zhou, Q.; Hou, M.; Ma, L.; Zhang, Z. Nanogap effects on near- and far-field plasmonic behaviors of metallic nanoparticle dimers. Phys. Chem. Chem. Phys. 2015, 17, 29293-29298. [CrossRef]

53. Schmid, M.; Grandidier, J.; Atwater, H.A. Scanning near-field optical microscopy on dense random assemblies of metal nanoparticles. J. Opt. 2013, 15, 125001. [CrossRef] 
54. Zito, G.; Rusciano, G.; Vecchione, A.; Pesce, G.; Girolamo, R.; Malafronte, A.; Sasso, A. Nanometal skin of plasmonic heterostructures for highly efficient near-field scattering probes. Sci. Rep. 2016, 6, 31113. [CrossRef]

55. Hoeing, D.; Schulz, F.; Mueller, N.S.; Reich, S.; Lange, H. Dark plasmon modes for efficient hot electron generation in multilayers of gold nanoparticles. Chem. Phys. 2020, 152, 064710. [CrossRef] [PubMed]

56. Humbert, C.; Pluchery, O.; Lacaze, E.; Tadjeddine, A.; Busson, B. Optical spectroscopy of functionalized gold nanoparticles assemblies as a function of the surface coverage. Gold Bull. (Berl. Ger.) 2013, 46, 299-309. [CrossRef]

57. Burrows, C.P.; Barnes, W.L. Large spectral extinction due to overlap of dipolar and quadrupolar plasmonic modes of metallic nanoparticles in arrays. Opt. Express 2010, 18, 3187-3198. [CrossRef]

58. Zhu, S.; Chen, T.P.; Liu, Z.; Liu, Y.C.; Liu, Y.; Yu, S.F. Optical properties of gold nanoparticles on heavily-doped Si substrate synthesized with an electrochemical process. J. Electrochem. Soc. 2011, 158, K152-K155. [CrossRef]

59. Losurdo, M.; Giangregorio, M.M.; Bianco, G.V.; Suvorova, A.A.; Kong, C.; Rubanov, S.; Capezzuto, P.; Humlicek, J.; Bruno, G. Size dependence of the dielectric function of silicon-supported plasmonic gold nanoparticles. Phys. Rev. B 2010, 82, 155451. [CrossRef]

60. Xiaoli, W.; Philippe, G.; Edmond, C.; Bruno, P. Near- and far-field effects on the plasmon coupling in gold nanoparticle arrays. J. Phys. Chem. C 2012, 116, 24741. [CrossRef]

61. Diaz-Egea, C.; Abargues, R.; Martínez-Pastor, J.P.; Sigle, W.; van Aken, P.A.; Molina, S.I. High spatial resolution mapping of individual and collective localized surface plasmon resonance modes of silver nanoparticle aggregates: Correlation to optical measurements. Nanoscale Res. Lett. 2015, 10, 310. [CrossRef]

62. Herrmann, L.O.; Valev, V.K.; Tserkezis, C.; Barnard, J.S.; Kasera, S.; Scherman, O.A.; Aizpurua, J.; Baumberg, J.J. Threading plasmonic nanoparticle strings with light. Nat. Commun. 2014, 5, 4568. [CrossRef]

63. Barrow, S.J.; Funston, A.M.; Gómez, D.E.; Davis, T.J.; Mulvaney, P. Surface plasmon resonances in strongly coupled gold nanosphere chains from monomer to hexamer. Nano Lett. 2011, 11, 4180-4187. [CrossRef]

64. Maksimenko, L.S.; Rudenko, S.P.; Stetsenko, M.O.; Matyash, I.E.; Mischuk, O.M.; Kolomzarov, Y.V.; Serdega, B.K. Diagnostic of resonant properties of Au-PTFE nanostructures for sensor applications. In Nanomaterials for Security; Bonča, J., Kruchinin, S., Eds.; NATO Science for Peace and Security Series A: Chemistry and Biology; Springer: Dordrecht, The Netherlands, 2016; pp. 267-280. [CrossRef]

65. Chandel, S.; Soni, J.; Ray, S.K.; Das, A.; Ghosh, A.; Raj, S.; Ghosh, N. Complete polarization characterization of single plasmonic nanoparticle enabled by a novel Dark-field Mueller matrix spectroscopy system. Sci. Rep. 2016, 6, 26466. [CrossRef] [PubMed]

66. Kravets, V.G.; Kabashin, A.V.; Barnes, W.L.; Grigorenko, A.N. Plasmonic surface lattice resonances: A review of properties and applications. Chem. Rev. 2018, 118, 5912-5951. [CrossRef] [PubMed]

67. Liu, S.-D.; Yue, P.; Zhang, S.; Wang, M.; Dai, H.; Chen, Y.; Nie, Z.-Q.; Cui, Y.; Han, J.-B.; Duan, H. Metasurfaces composed of plasmonic molecules: Hybridization between parallel and orthogonal surface lattice resonances. Adv. Opt. Mater. 2019, 8, 1901109. [CrossRef]

68. Hao, F.; Sonnefraud, Y.; Dorpe, P.V.; Maier, S.A.; Halas, N.J.; Nordlander, P. Symmetry breaking in plasmonic nanocavities: Subradiant LSPR sensing and a tunable fano resonance. Nano Lett. 2008, 8, 3983-3988. [CrossRef]

69. Gerrard, A.; Burch, J.M. Introduction to Matrix Methods in Optics; Dover Publications: Mineola, NY, USA, 2012; p. 384.

70. Ma, W.; Xu, L.; de Moura, A.F.; Wu, X.; Kuang, H.; Xu, C.; Kotov, N.A. Chiral inorganic nanostructures. Chem. Rev. 2017, 117, 8041-8093. [CrossRef]

(C) 2020 by the authors. Licensee MDPI, Basel, Switzerland. This article is an open access article distributed under the terms and conditions of the Creative Commons Attribution (CC BY) license (http://creativecommons.org/licenses/by/4.0/). 